\title{
Long-Term Regulation of Adipocyte Glucose Transport Capacity by Circulating Insulin in Rats
}

\author{
Masashi Kobayashi and Jerrold M. Olefsky, Department of Medicine, \\ Stanford University School of Medicine, Stanford University, \\ Stanford, California 94305
}

\begin{abstract}
A B S T RACT We have tested the idea that the circulating plasma insulin level plays an important role in the long-term regulation, or maintenance, of the cellular glucose transport system, distinct from insulin's ability to acutely accelerate glucose transport. To study this hypothesis, groups of rats were made either hyperinsulinemic or hypoinsulinemic by daily insulin injections, or streptozotocin treatment, respectively. Different levels of hypoinsulinemia were produced by using different doses of streptozotocin $(40$ and $55 \mathrm{mg} / \mathrm{kg})$. The mean $( \pm \mathrm{SE}) 9$ a.m. plasma insulin level for each experimental group was: hyperinsulinemic animals, $65 \pm 5$ $\mu \mathrm{U} / \mathrm{ml}$; controls, $32 \pm 3 \mu \mathrm{U} / \mathrm{ml}$; low dose streptozotocin group, $18 \pm 3 \mu \mathrm{U} / \mathrm{ml}$; and high dose streptozotocin group $5 \pm 2 \mu \mathrm{U} / \mathrm{ml}$. Isolated adipocytes were prepared from each animal and glucose transport was assessed by measuring the initial rates of uptake of the nonmetabolyzable hexose 2-deoxy glucose. The $V_{\max }$ and $K_{m}$ values for adipocyte glucose transport were calculated from the 2-deoxy glucose uptake data. The results demonstrated that in cells from control animals the $V_{\max }$ of in vitro adipocyte glucose transport was $7.1 \pm 0.7 \mathrm{nmol} /$ min per $10^{6}$ cells in the basal state and $22.9 \pm 0.9 \mathrm{nmol} /$ min per $10^{6}$ cells in the presence of a maximally effective insulin concentration $(25 \mathrm{ng} / \mathrm{ml})$ in the buffer. In cells from the experimentally hyperinsulinemic animals these $V_{\max }$ values were increased to $11.7 \pm 0.8$ and $44.2 \pm 1.1 \mathrm{nmol} / \mathrm{min}$ per $10^{6}$ cells. Using adipocytes from both groups of streptozotocin-treated (high dose, $55 \mathrm{mg} / \mathrm{kg}$; low dose, $40 \mathrm{mg} / \mathrm{kg}$ ) insulin-deficient diabetic animals, $V_{\max }$ values were found to be progressively decreased. Thus, in the low dose group, basal-and in-
\end{abstract}

Dr. Kobayashi was a National Institutes of Health postdoctoral Trainee supported by the National Institute of Arthritis, Metabolic, and Digestive Diseases (NIH) training grant AM 07217 during the course of these studies. Dr. Olefsky is a Clinical Investigator with the Veterans Administration. Dr. Olefsky's present address is University of Colorado School of Medicine, Department of Medicine, Denver, Colo.

Received for publication 5 October 1977 and in revised form 5 January 1978. sulin-stimulated $V_{\max }$ values were $1.6 \pm 0.5$ and $5.7 \pm 0.7$ $\mathrm{nmol} / \mathrm{min}$ per $10^{6}$ cells, as compared to values of $0.9 \pm 0.2$ and $1.7 \pm 0.6$ in the high dose group. Thus, when considered as group data a positive relationship was found between circulating plasma insulin levels and adipocyte glucose transport $V_{\text {max }}$, with increased $V_{\max }$ values in hyperinsulinemic rats and decreased $V_{\max }$ values in hypoinsulinemic rats. Furthermore, when the individual data were analyzed, highly significant correlation coefficients were found between the height of the plasma insulin level and both the basal $(r=0.82, P<0.001)$ and insulin-stimulated $(r=0.93, P<0.001) V_{\max }$ values. The apparent $K_{m}$ for 2-deoxy glucose uptake was the same under all conditions.

In conclusion, assuming that the $V_{\max }$ of transport is some function of the number of glucose transport carriers per cell, then these results support the hypothesis that in addition to acute acceleration of glucose transport, insulin is also an important long-term regulator of the number of available adipocyte glucose transport carriers.

\section{INTRODUCTION}

Insulin stimulates the carrier-mediated transport of glucose in a number of cell types, and this process is an important rate controlling step in glucose metabolism (1). Although the precise mechanism of insulin's ability to accelerate glucose transport is not known, it has been demonstrated that a very brief exposure to insulin promotes glucose transport by increasing the $V_{\max }$ of the transport process without changing the $K_{m}$ (2-4). Because of the short exposure time necessary for this effect, it is thought that insulin activates existing transport units (5) and does not promote the synthesis of new carrier proteins. Thus, this process provides a means whereby insulin can acutely regulate glucose metabolism. On the other hand, it seems possible that insulin may also play a role in the long-term regulation, or maintenance, of the glucose transport system. For example, we have found that fasting leads to a pro- 
gressive decrease in the $V_{\max }$ of adipocyte glucose transport and that the decline in maximal transport capacity correlated quite well with the fasting-induced fall in plasma insulin levels (6). Furthermore, Kipnis et al. $(7,8)$ and Morgan et al. $(9,10)$ have demonstrated that alloxan-induced diabetes leads to decreased glucose transport in the rat diaphragm $(7,8)$ and heart muscle $(9,10)$. Thus, there is some precedent to suspect that hypoinsulinemic states may be associated with depressed glucose transport activity. Additionally, Smith (11) has reported that when adipocytes are cultured in the presence of insulin for $1 \mathrm{wk}$, the cells subsequently have an increased capacity for glucose uptake and metabolism compared to control cells cultured in the absence of insulin. Thus, it is our hypothesis that the level of insulin to which cells are chronically exposed plays an important role in the long-term regulation of the capacity of the glucose transport system. If one assumes that the transport $V_{\max }$ is some function of the number of glucose transport units per cell (5), then our hypothesis would be that the height of the plasma insulin level regulates the number of available carrier proteins in the plasma membranes of target cells. To test this idea we have chronically modified the in vivo plasma insulin level in rats by various treatments and have simultaneously assessed the $V_{\max }$ of adipocyte glucose transport. The results demonstrate, that under all circumstances there is an excellent correlation between the height of the in vivo plasma insulin level and the in vitro adipocyte transport $V_{\max }$.

\section{METHODS}

Materials. Porcine monocomponent insulin was generously supplied by Dr. Ronald Chance of the Eli Lilly \& Co. (Indianapolis, Ind.). Bovine serum albumin (fraction V) was purchased from Armour Pharmaceutical Co. (Chicago, Ill.), collagenase from Worthington Biochemical Corp. (Freehold, N. J.), 2-deoxy $\left[1-{ }^{14} \mathrm{C}\right]$ glucose and $\left[{ }^{14} \mathrm{C}\right]$ inulin from New England Nuclear (Boston, Mass.), streptozotocin from ICN Pharmaceuticals, Inc., Life Sciences Group (Cleveland, Ohio), and Neutral protamine Hagedorn insulin from Eli Lilly \& Co.

Animals. Male Sprague-Dawley rats were used for all experiments.

Hyperinsulinemic rats. The experimentally hyperinsulinemic rats were prepared by dividing 110-120:g rats into two groups. One group was injected subcutaneously with Neutral protamine Hagedorn insulin every $12 \mathrm{~h}$ (9 a.m. and 9 p.m.), in gradually increasing dosages (from $0.5 \mathrm{U}$ to $6 \mathrm{U} / \mathrm{day}$ ) for 14 days. Two-thirds of the daily amount of insulin was given at 9 p.m., and one-third at 9 a.m. An identical volume of Neutral protamine Hagedorn insulin diluting solution was injected into control animals. To prevent hypoglycemia, all animals had free access to sugar cubes and $5 \%$ glucose drinking water, in addition to normal rat chow. Both groups were fed ad lib until the morning of all studies. On day 15 , rats were sacrificed and blood was collected for the determination of plasma glucose and insulin.

Insulin-deficient rats. Insulin-deficient diabetes was induced by injecting rats (via tail vein) with streptozotocin
$(\mathrm{STZ})^{1}$ prepared in citrate buffer, $\mathrm{pH}$ 4.0. Animals weighing 160-170 g were divided into three groups. The first, or high dose group, was injected with $55 \mathrm{mg} / \mathrm{kg} \mathrm{STZ}$; the second, or low dose group, was injected with $40 \mathrm{mg} / \mathrm{kg} \mathrm{STZ}$; and the third, or control group, was given an identical volume of citrate buffer. 7 days after the injection, animals were sacrificed and blood was collected for determination of plasma glucose and insulin. All groups were fed ad lib until the morning of all studies. Food intake and body weight were measured daily. Because the results from the control groups for the hyperinsulinemic rats and the STZ-treated groups were similar, the data from the two control groups have been combined.

Hyperglycemic, Noninsulin-deficient rats. To produce hyperglycemia in the absence of hypoinsulinemia an additional series of rats, weighing $160 \mathrm{~g}$ initially, were treated with $3-\mathrm{ml}$ injections of a $30 \%$ glucose solution intraperitoneally at 8 a.m., 3 p.m., and 9 p.m. for 7 days. Tail vein blood was obtained for determination of plasma glucose levels before each injection.

Preparation of isolated adipocytes. All studies were begun at 9 a.m. Animals were stunned by a blow to the head, decapitated, and epididymal fat pads were removed. Isolated fat cells were prepared by shaking at $37^{\circ} \mathrm{C}$ for $60 \mathrm{~min}$ in Krebs-Ringer bicarbonate buffer containing collagenase $(3 \mathrm{mg} / \mathrm{ml})$ and bovine serum albumin $(40 \mathrm{mg} / \mathrm{ml})$ according to the method of Rodbell (12). Cells were filtered through $250 \mu \mathrm{M}$ nylon mesh, centrifuged at $400 \mathrm{rpm}$ for 4 min, and washed twice in buffer (13). Adipocyte counts were performed according to a modification of method III of Hirsch and Gallian (14), in which the cells were fixed in $2 \%$ osmium tetroxide in $0.05 \mathrm{M}$ collidine buffer (made isotonic with saline) for $24 \mathrm{~h}$ at $37^{\circ} \mathrm{C}$ and then taken up in a known volume of $0.154 \mathrm{M} \mathrm{NaCl}$ for counting with a Coulter counter model ZB (Coulter Electronics, Inc., Hialeah, Fla.). Adipocyte size was determined with a calibrated microscope by the method of $\mathrm{Di}$ Girolamo et al. (15).

Glucose transport studies. Transport studies were performed by measuring the initial uptake rates of 2-deoxy glucose. The details and validation of this method have been described $(4-6,16)$. Briefly, isolated adipocytes were incubated with 2 -deoxy-D-[1-14 C]glucose $(2 \mathrm{mCi} / \mathrm{mM} \mathrm{sp}$ act $)$ at various concentrations in Krebs-Ringer bicarbonate buffer, $\mathrm{pH} 7.4$, containing bovine serum albumin $(10 \mathrm{mg} / \mathrm{ml})$ at $24^{\circ} \mathrm{C}$. The assay measures the total uptake of the radiolabeled 2-deoxy glucose and is based on the principle that although 2-deoxy glucose is transported and phosphorylated by the same process as D-glucose it cannot be further metabolized (17). The assay is terminated at the end of $3 \mathrm{~min}$ by transferring $200-\mu \mathrm{l}$ aliquots from the assay mixture to plastic microtubes containing $100 \mu \mathrm{l}$ silicone oil. The tubes are centrifuged for $30 \mathrm{~s}$ in a Beckman microfuge (Beckman Instruments, Inc., Spinco Div., Palo Alto, Calif.), and the assay is considered terminated when centrifugation begins. In experiments in which the stimulatory effect of insulin on uptake was measured, the cells were preincubated with a maximally effective insulin concentration $(25 \mathrm{ng} / \mathrm{ml})$ for 45 mins at $24^{\circ} \mathrm{C}$. The amount of sugar trapped in the extracellular water space of the cell layers was determined using $\left[{ }^{14} \mathrm{C}\right]$ inulin according to the method of Gliemann (18) et al. Extracellular water space is measured in each experiment, and all data of sugar uptake are corrected for this factor. The percent of the total amount of sugar available which was

\footnotetext{
${ }^{1}$ Abbreviation used in this paper: STZ, streptozotocin.
} 
trapped in the extracellular water space averaged $0.033 \pm 0.001$ at a concentration of $2 \times 10^{5} \mathrm{cells} / \mathrm{ml}$. The amount of trapped sugar ranged from $2-10 \%$ of the total sugar uptake depending on the conditions of incubation.

Measurement of intracellular 2-deoxy glucose and a 2-deoxy glucose-phosphate levels. Intracellular 2-deoxy glucose and 2-deoxy glucose-phosphate were measured by a modification of the method of Tsuboi and Petricciani (19) as described (5). Cells were incubated with $\left[{ }^{14} \mathrm{C}\right] 2$-deoxy glucose in $0.5 \mathrm{ml}$ and uptake was stopped by the addition of $3 \mathrm{ml}$ iced Krebs-Ringer buffer containing $1 \mathrm{mM}$ unlabeled 2-deoxy glucose. Cells were isolated, disrupted in boiling water and intracellular hexose was determined by anion exchange chromatography using a Dowex $1-\mathrm{X} 8$ column (Dow Chemical Co., Midland, Mich.). The intracellular water volume was determined by simultaneous assessment of the sucrose and 3-O-methyl glucose spaces. The 3-O-methyl glucose space (total water) minus the sucrose space (extracellular water) equals the intracellular water space. By knowing the number of cells present, and the amount of 2-deoxy glucose and phosphorylated sugar per cell, the intracellular concentrations of these substances can be calculated.

Analytical methods. Plasma glucose was determined by the glucose oxidase method using a Beckman Glucose Analyzer (Beckman Instruments), and plasma insulin was determined by the technique of Desbuquois and Aurbach (20).

Statistical analysis. All P values were obtained by use of a nonpaired $t$ test. Correlation coefficients were derived by the Pearson product moment method.

\section{RESULTS}

Experimental animals. Some characteristics of the experimental animals are presented in Table I. As can be seen, daily weight gain and food consumption were identical in control, insulin-, and glucosetreated animals. Daily weight gain of the high dose $(55 \mathrm{mg} / \mathrm{kg}$ ) STZ-treated animals was markedly less than control, despite normal food intake, whereas the low dose group $(40 \mathrm{mg} / \mathrm{kg})$ gained weight at a near normal rate. Thus, in this latter group significant negative caloric balance was absent despite moderate insulin deficiency. Fat cell size was increased in the insulintreated group, and decreased in the STZ-treated animals. Plasma insulin levels were measured at 9 a.m.

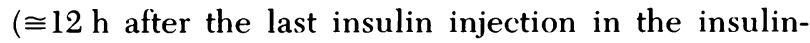
treated animals), and were significantly increased in the insulin-treated animals and significantly decreased in both STZ-treated groups.

Experimentally hyperinsulinemic rats. Fig. 1 summarizes the glucose transport studies performed on isolated adipocytes from the experimentally hyperinsulinemic and control animals. 2-deoxy glucose uptake was studied over a wide range of hexose concentrations in the absence and presence of a maximally effective insulin level $(25 \mathrm{ng} / \mathrm{ml})$ in the buffer. In the presence of insulin, adipocytes from the experimentally hyperinsulinemic animals took up markedly more 2-deoxy glucose at all hexose concentrations. Although less striking, basal rates of 2-deoxy glucose uptake were also significantly higher for the hyperinsulinemic group. The shape of the curves in Fig. 1 demonstrates two uptake components: a saturable component seen at 2-deoxy glucose concentrations $<5 \mathrm{mM}$, and a nonsaturable, linear component seen at higher sugar concentrations. The nonsaturable process represents simple inward diffusion of labeled hexose $(4,16,21-24)$, and these uptake data can be corrected for this diffusion process by subtracting the contribution of this linear component from the total uptake at each point. When these corrected data are submitted to Lineweaver-Burk analysis, apparent $K_{m}$ and $V_{\max }$ values can be calculated. With this approach (Fig. 2 and Table II) the apparent $K_{m}$ of 2-deoxy glucose uptake is comparable in both groups $(2.5-2.8$

TABLE I

Characteristics of Experimental Animals

\begin{tabular}{|c|c|c|c|c|c|}
\hline & \multirow{2}{*}{$\begin{array}{l}\text { Control } \\
(n=21)\end{array}$} & \multirow{2}{*}{$\begin{array}{l}\text { Insulin treated } \\
\quad(n=23)\end{array}$} & \multicolumn{2}{|c|}{ Streptozotocin treated } & \multirow{2}{*}{$\begin{array}{l}\text { Glucose injected } \\
\qquad(n=3)\end{array}$} \\
\hline & & & $(n=12)$ & $(n=5)$ & \\
\hline & & & $40 \mathrm{mg} / \mathrm{kg}$ & $55 \mathrm{mg} / \mathrm{kg}$ & \\
\hline Body weight, $g$ & $206 \pm 8$ & $208 \pm 9$ & $202 \pm 3$ & $162 \pm 8$ & $207 \pm 4$ \\
\hline Weight gain, g/day & $6.6 \pm 0.7$ & $6.7 \pm 0.5$ & $5.1 \pm 0.8$ & $0.7 \pm 0.9$ & $6.5 \pm 0.7$ \\
\hline Food intake, g/day & $19.9 \pm 0.7 \S$ & $20.8 \pm 0.6 \S$ & $23.1 \pm 2.0$ & $24.6 \pm 1.4$ & $20.3 \pm 1.8$ \\
\hline Cell size, $p l$ & $71 \pm 5$ & $107 \pm 7$ & $50 \pm 3$ & $27 \pm 3$ & $73 \pm 8$ \\
\hline Cell surface area, $\times 10^{3} \mu M^{2}$ & $8.4 \pm 0.6$ & $10.5 \pm 0.6$ & $6.5 \pm 0.2$ & $4.3 \pm 0.2$ & $8.4 \pm 0.7$ \\
\hline Plasma glucose, ${ }^{*} \mathrm{mg} / \mathrm{ml}$ & $138 \pm 4$ & $82 \pm 6$ & $218 \pm 38$ & $503 \pm 31$ & $178 \pm 6$ \\
\hline Plasma insulin, ${ }^{*} \mu U / m l$ & $32 \pm 3$ & $65 \pm 5$ & $18 \pm 3$ & $5 \pm 2$ & $44 \pm 4$ \\
\hline
\end{tabular}

* These values are measured at 9 a.m. on the day of experiments.

$\$$ This is the mean 9 a.m. value on the date of experiments. The values before each glucose injection were $181 \pm 8 \mathrm{mg} / 100 \mathrm{ml}$ at 8 a.m., $203 \pm 11 \mathrm{mg} / 100 \mathrm{ml}$ at $3 \mathrm{p} . \mathrm{m}$. and $214 \pm 10 \mathrm{mg} / 100$ at 9 p.m.

$\$$ In addition to rat chow the hyperinsulinemic animals consumed $1.3 \pm 0.5 \mathrm{~g} / \mathrm{day}$ of sugar cubes and drank $43 \pm 4 \mathrm{ml} /$ day $5 \%$ glucose drinking water. Control animals for this group ingested $1.2 \pm 0.3 \mathrm{~g} /$ day sugar cubes and drank $46 \pm 3 \mathrm{ml} /$ day $5 \%$ glucose in water. 




Figure 1 Effect of substrate concentration on 2-deoxy glucose uptake by cells from control $(\Theta)$ and insulin-treated (O) rats in the basal $(-)$ and insulin-stimulated state $(---)$. Cells were preincubated with or without a maximally effective insulin concentration $(25 \mathrm{ng} / \mathrm{ml})$ for $45 \mathrm{~min}$ at $24^{\circ} \mathrm{C}$. Uptake was then measured at the end of a 3-min incubation with 2-deoxy glucose at the indicated concentrations. At 2deoxy glucose concentrations $>5 \mathrm{mM}$ the slopes of the lines represent simple inward diffusion of the sugar into the cells (4, 17-20); the data can be corrected for this linear diffusion component by subtracting the contribution of this linear process from the absolute values $(4,17-20)$. Results represent the mean $( \pm \mathrm{SE})$ of five separate experiments for the hyperinsulinemic group and eight for the control group.

$\mathrm{mM}$ ) of cells in the presence or absence of insulin. On the other hand, the $V_{\max }$ value for insulinstimulated glucose transport is $44.2 \pm 1.1 \mathrm{nmol} / \mathrm{min}$ per $10^{6}$ cells in the hyperinsulinemic group and this is almost twofold greater than the $V_{\max }$ value for control cells $\left(22.9 \pm 0.9 \mathrm{nmol} / \mathrm{min}\right.$ per $\left.10^{6} \mathrm{cells}\right)$. The basal $V_{\max }$ value also increased from $7.1 \pm 0.7$ to $11.7 \pm 0.8 \mathrm{nmol} /$ min per $10^{6}$ cells. Thus, chronic hyperinsulinemia is associated with an increase in the adipocyte glucose transport system, per se, and this is mediated through an increase in $V_{\max }$ with no change in the $K_{m}$ value.

Glucose-treated hyperinsulinemic rats. Although

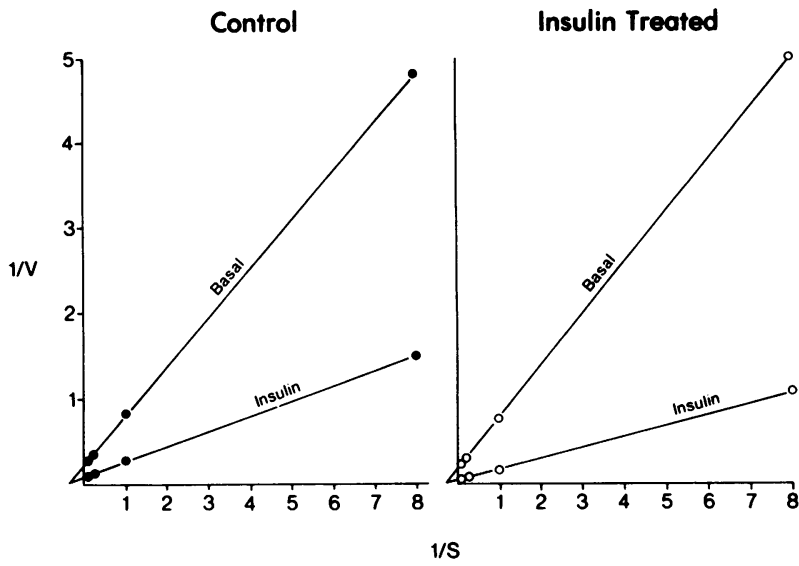

Figure 2 Lineweaver-Burk plot of the corrected data from Fig. 1 for control and insulin-treated rats. The calculated "apparent" $K_{m}$ and $V_{\max }$ values are given in Table II.

actual hypoglycemia was not a feature of the hyperinsulinemic animals, the plasma glucose levels were lower (Table I) in the insulin-treated group and it is possible to suggest that lower plasma glucose levels and (or) exaggerated counter regulatory hormonal responses, rather than the hyperinsulinemia, might account for the increase in transport $V_{\max }$. To control for these potential variables, a group of insulintreated animals was also given glucose injections to avoid decreased plasma glucose levels and inhibit counter regulatory mechanisms. In these animals a solution of $20 \%$ glucose was injected $(0.75 \mathrm{~g})$ i.p. at 12 midnight, 7 a.m. $(0.5 \mathrm{~g}), 1$ p.m. $(0.5 \mathrm{~g})$ and 6 p.m. $(0.5 \mathrm{~g})$, while Neutral Protamine Hagedorn insulin was injected subcutaneously twice a day at 9 a.m. and 9 p.m. Plasma glucose levels were measured before each glucose injection and were $112 \pm 8(\mathrm{SE})$ $\mathrm{mg} / 100 \mathrm{ml}$ at 7 a.m., $94 \pm 10 \mathrm{mg} / 100 \mathrm{ml}$ at 1 p.m., $125 \pm 6 \mathrm{mg} / 100 \mathrm{ml}$ at $6 \mathrm{p} . \mathrm{m}$. and $142 \pm 15 \mathrm{mg} / 100 \mathrm{ml}$

TABLE II

Mean $( \pm S E) K_{m}$ and $V_{\max }$ Values

\begin{tabular}{|c|c|c|c|c|c|c|}
\hline & \multicolumn{2}{|c|}{$K_{m}$} & \multicolumn{2}{|c|}{$V_{\max }$} & \multicolumn{2}{|c|}{$V_{\max }$} \\
\hline & Basal & + Insulin & Basal & +Insulin & Basal & +Insulin \\
\hline & & & \multicolumn{2}{|c|}{ nmol/min $/ 10^{8}$ cells } & \multicolumn{2}{|c|}{$\mathrm{nmol} / \mathrm{min} / 10 \mathrm{~cm}^{2}$} \\
\hline Control & 2.5 & 2.8 & $7.1 \pm 0.7$ & $22.9 \pm 0.9$ & $8.4 \pm 0.8$ & $27.2 \pm 1.1$ \\
\hline Hyperinsulinemic & 2.6 & 2.8 & $11.7 \pm 0.8$ & $44.2 \pm 1.1$ & $11.1 \pm 0.5$ & $40.4 \pm 1.0$ \\
\hline \multicolumn{7}{|c|}{ Streptozotocin treated } \\
\hline $40 \mathrm{mg} / \mathrm{kg}$ & 2.9 & 2.8 & $1.6 \pm 0.5$ & $5.7 \pm 0.7$ & $2.4 \pm 0.8$ & $8.7 \pm 1.0$ \\
\hline $55 \mathrm{mg} / \mathrm{kg}$ & 3.0 & 2.9 & $0.9 \pm 0.2$ & $1.7 \pm 0.6$ & $2.1 \pm 0.4$ & $4.0 \pm 1.4$ \\
\hline Glucose injected* & 2.6 & 2.7 & $6.6 \pm 0.1$ & $21.4 \pm 0.4$ & $7.9 \pm 0.1$ & $25.3 \pm 0.5$ \\
\hline
\end{tabular}

* It should be noted that although these rats had modestly elevated plasma insulin levels, adipocyte glucose transport was not increased. The explanation for this is not clear and we can only surmise that the degree of hyperinsulinemia achieved was not sufficient to produce detectable changes in transport capacity. 


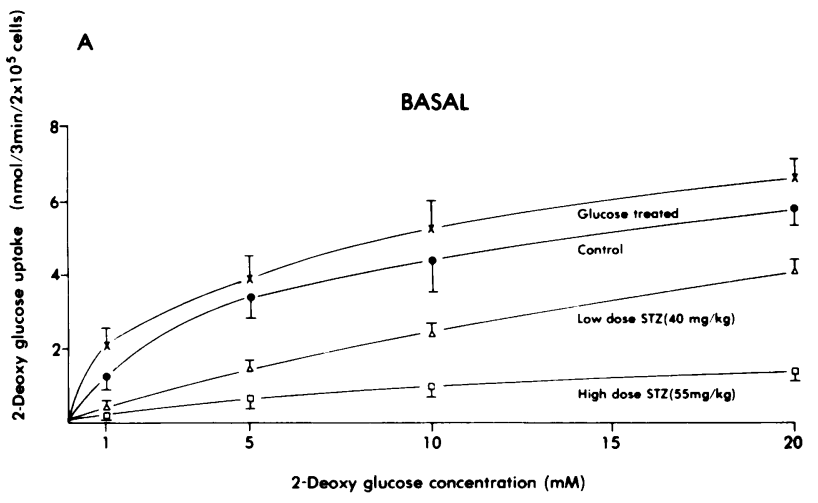

B

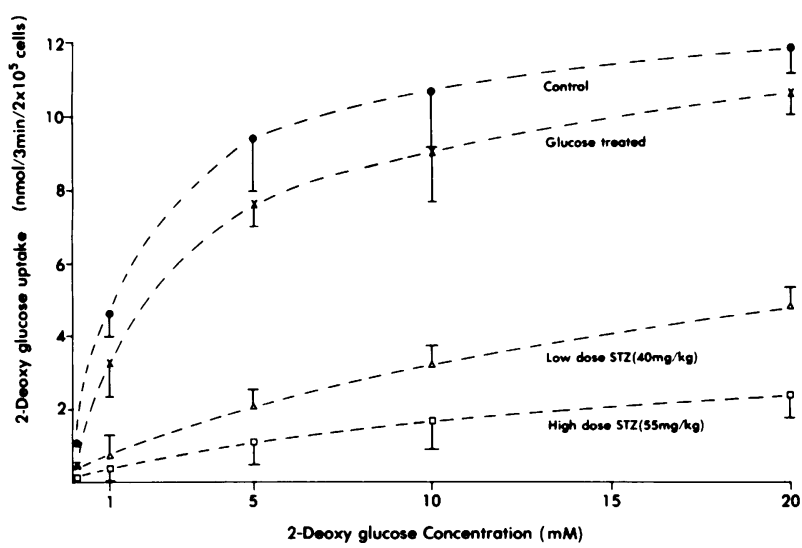

FIgURE 3 Effect of substrate concentration on 2-deoxy glucose uptake by cells from the low dose STZ $(\triangle)$, high dose STZ $(\square)$, and glucose-injected $(x)$ rats in the absence (basal state) of insulin (A), and in the presence (B) of a maximally effective insulin level $(25 \mathrm{ng} / \mathrm{ml})$. Data represent the mean $( \pm S E)$ of 6,5 , and 3 separate experiments for the low dose STZ, high dose STZ, and glucose-injected rats, respectively.

at 12 midnight. ${ }^{2}$ Because rats consume most of their food between midnight and 7 a.m., and since the plasma glucose values were measured when the hyperglycemic effect of the preceeding glucose injection was least, these glucose levels represent the lowest values in the daily plasma glucose profile. Thus, these experimentally hyperinsulinemic animals were clearly not hypoglycemia, but were actually somewhat hyperglycemic compared to controls. In these animals, glucose transport was found to be similar to the values found in the experimentally hyperinsulinemic rats in both basal and insulin-stimulated states (data not shown). Therefore chronic hyperinsulinemia, rather than lower plasma glucose levels or counter

${ }^{2}$ These should be compared to plasma glucose values in normal rats of $119 \pm 5,102 \pm 9,98 \pm 6$, and $91 \pm 4 \mathrm{mg} / 100 \mathrm{ml}$ at 7 a.m., 1 p.m., 6 p.m., and midnight respectively. regulatory hormonal responses, appears to be most closely associated with the increase in $V_{\max }$.

STZ-treated rats. The ability of adipocytes from STZ-, glucose-treated, and control rats to take up 2deoxy glucose is shown in Fig. 3. 2-deoxy glucose uptake is clearly decreased in both STZ-treated diabetic groups, and this decrease is greater in the more insulin-deficient diabetic animals who received the higher dose $(55 \mathrm{mg} / \mathrm{kg})$ of STZ. When the data from Fig. 3 were analyzed on a Lineweaver-Burk plot (Fig. 4), the $V_{\max }$ values were lower in the STZtreated diabetic animals and the magnitude of this decrease in $V_{\max }$ was greater in the more hypoinsulinemic group. On the other hand, the $K_{m}$ value was unchanged in any of the experimental conditions. It should be noted that in the low dose STZ group, the slope of the nonsaturable component is increased, at least in the basal state, and the reason for this is unexplained. Because this leads to a higher proportion of total uptake accounted for by diffusion, this curve (Fig. 3A, low dose STZ) is less suitable than the other uptake curves for kinetic analysis.

An additional group of rats was given glucose injections designed to approximate the degree of hyperglycemia seen in the diabetic rats who received the low dose of STZ. These animals were given $3 \mathrm{ml}$ of a $30 \%$ glucose solution i.p. at 8 a.m., 3 p.m., and 9 p.m. Mean plasma glucose values just before each injection were 178,210 , and $210 \mathrm{mg} / 100 \mathrm{ml}$, respectively, and these values represent the minimum level of hyperglycemia throughout the day since they were obtained when the glycemic effect of the preceeding glucose injection was least. Although these rats were



FigURE 4 Lineweaver-Burk plot of Fig. 3 for the basal (A) and insulin-stimulated (B) states. The calculated "apparent" $K_{m}$ and $V_{\max }$ values are given in Table II. 
hyperglycemic, they clearly were not hypoinsulinemic, and adipocyte 2-deoxy glucose uptake in these animals (Figs. 3 and 4) was normal. Thus, the decrease in glucose transport seen in the STZ-treated rats is best correlated with the hypoinsulinemia rather than the hyperglycemia.

The data from all of the 2-deoxy glucose uptake studies are summarized in Table II. As can be seen, $K_{m}$ values are comparable in all conditions, while $V_{\max }$ values are greater in the hyperinsulinemic animals and less in the hypoinsulinemic animals. It should be noted that all of the above data are expressed per cell, and because glucose transport is a membrane phenomenon, the surface area of adipocytes may be an important factor to consider in the data analysis. This is especially relevant since adipocyte size (and consequently surface area) was different among the experimental groups. However, as can be seen in the right hand column of Table II, expressing the data on the basis of plasma membrane surface area does not change any of the relationships between the $V_{\max }$ values and the plasma insulin levels.

Validity of 2-deoxy glucose uptake as a measure of glucose transport. Because 2-deoxy glucose can be phosphorylated as well as transported, it is important to determine that hexokinase activity does not influence the initial rates of 2-deoxy glucose uptake. Theoretically, uptake represents the balance between sugar influx and efflux, and to assess initial transport rates it is essential to measure influx under circumstances where efflux is minimal or nonexistent. If hexokinase activity were rate determining for 2deoxy glucose uptake, at any time during the experiment, then there would be significant accumulation of intracellular unphosphorylated 2-deoxy glucose. Because phosphorylated sugars are "trapped" within the cell and only the unphosphorylated hexose can efflux, if hexokinase activity were limiting, net uptake of 2deoxy glucose would not be a linear function of time. However, time-course studies have shown that 2-deoxy glucose uptake is strictly linear with time under all the experimental conditions employed (data not shown, also see ref. 5). Thus, this demonstrates that true unidirectional flux is being measured rather than net flux complicated by significant sugar efflux.

This contention can be tested more directly by measuring the intracellular concentrations of 2-deoxy glucose, and 2-deoxy glucose-phosphate at the time net uptake is assessed. These data are provided in Table III. As can be seen intracellular levels of free 2-deoxy glucose are absent or minimal compared to the extracellular levels in normal and experimental animals. Therefore, because efflux is concentration dependent (3), 2-deoxy glucose efflux must be minimal relative to influx. From these and other (5) studies, we believe that initial rates of 2 -deoxy glucose uptake provide a valid and quantitative measure of adipocyte glucose transport.

Relationship between $V_{\max }$ and plasma insulin levels. As shown in Table II, an increased $V_{\max }$ was found in adipocytes from insulin-treated hyperinsulinemic rats, and a decreased $V_{\max }$ was seen in adipocytes from hypoinsulinemic rats. This is consistent with the idea that the ambient plasma insulin level is an important factor in the long-term regulation of the cell's overall capacity for glucose transport. This idea is further supported when the individual data are analyzed. Thus, when the $V_{\max }$ values are plotted against the plasma insulin levels of the individual animals from each study group (Fig. 5), an excellent correlation was found between the height of the plasma insulin level and the $V_{\max }$ of glucose transport in both the basal $(r=0.82, P<0.001)$ and insulin-stimulated state $(r=0.93, P<0.001)$.

\section{DISCUSSION}

It is well recognized that insulin can acutely promote carrier-mediated glucose transport in insulin sensitive tissues by increasing the $V_{\max }$ of the transport process (1-4). Recently, we have provided evidence indicating that this acute stimulatory effect is mediated by an increase in the number of functioning carriers (5). Because full stimulation of transport is seen within a few

TABLE III

Comparison of Extracellular and Intracellular 2-Deoxy Glucose Concentrations

\begin{tabular}{|c|c|c|c|}
\hline & \multirow{2}{*}{$\begin{array}{c}\text { Medium } \\
\text { 2-deoxy glucose } \\
\text { concentration }\end{array}$} & \multicolumn{2}{|c|}{$\begin{array}{l}\text { Intracellular 2-deoxy } \\
\text { glucose concen- } \\
\text { tration }(\mathrm{mM})^{*}\end{array}$} \\
\hline & & Basal & $\begin{array}{c}\text { Insulin } \\
\text { stimulated }\end{array}$ \\
\hline & $m M$ & & $25 \mathrm{ng} / \mathrm{ml}$ \\
\hline \multirow[t]{2}{*}{ Normal } & 1 & $0 \ddagger$ & 0 \\
\hline & 10 & 0.25 & 0.48 \\
\hline \multirow[t]{2}{*}{ Hyperinsulinemic } & 1 & 0 & 0.04 \\
\hline & 10 & 0.28 & 0.59 \\
\hline \multirow[t]{2}{*}{ Low dose STZ, $40 \mathrm{mg} / \mathrm{kg}$} & 1 & 0 & 0 \\
\hline & 10 & 0.11 & 0.27 \\
\hline \multirow[t]{2}{*}{ High dose STZ, $55 \mathrm{mg} / \mathrm{kg}$} & 1 & 0 & 0 \\
\hline & 10 & 0 & 0.12 \\
\hline
\end{tabular}

* In all cases intracellular 2-deoxy glucose accounted for $<10 \%$ of the total uptake, and therefore $>90 \%$ of the intracellular hexose was in the phosphorylated form.

\$ Although no intracellular 2-deoxy glucose was detected under these conditions it is likely that some was present. However, the level of this sugar would be negligible because intracellular concentrations as low as $0.01 \mathrm{mM}$ are readily measureable. 


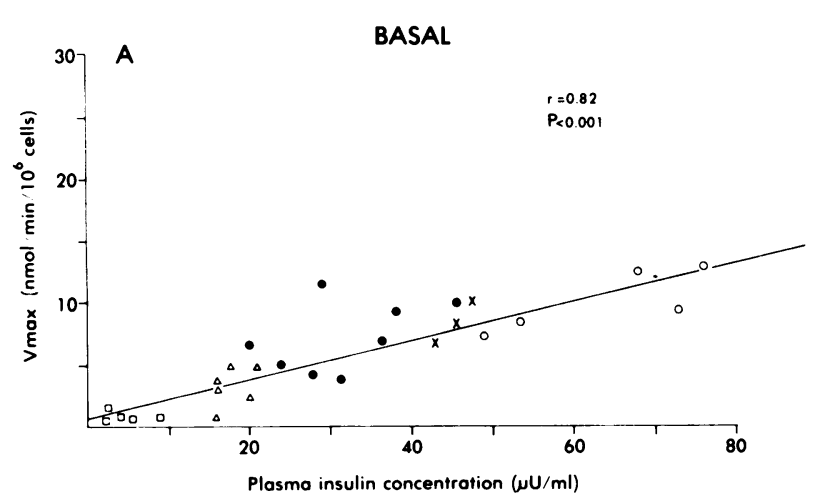

B

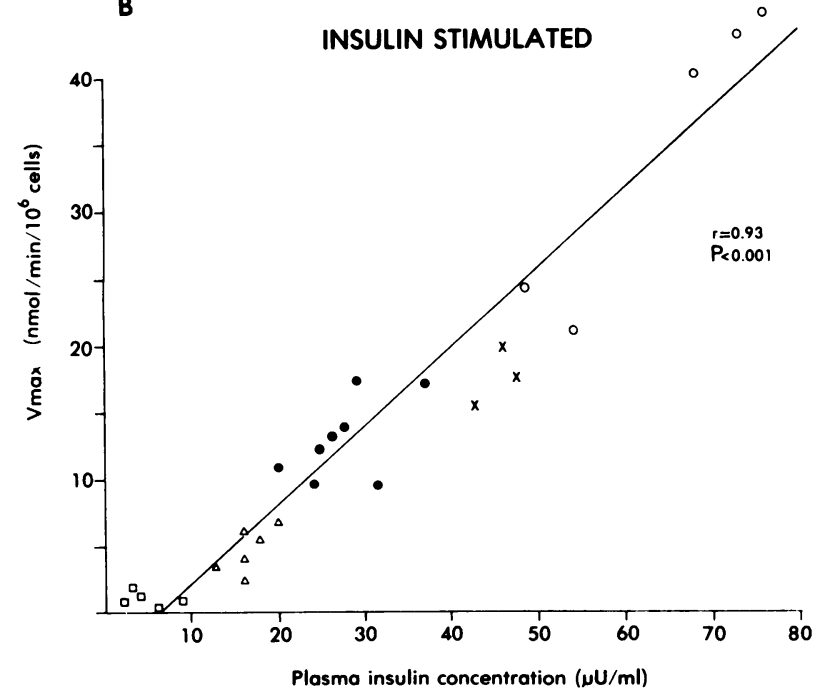

FIGURE 5 Relationship between the plasma insulin level and the $V_{\max }$ of adipocyte 2-deoxy glucose transport for all individual animals studied. Symbols represent insulin-treated $(\bigcirc)$, glucose-injected $(\times)$, control $(\odot)$, high dose STZ $(\square)$, and low dose STZ $(\triangle)$ groups. The linear regression equations were $y=0.15 x+0.88$ for the basal state and $y=0.59$ $x-3.82$ for the insulin-stimulated state.

minutes of exposure to insulin, this process is most likely a result of activation of already existing, but inactive, glucose transport units (5). In this study we have examined the idea that insulin also functions in the long-term regulation, or maintenance, of the glucose transport system. Thus, it is our hypothesis that the circulating plasma insulin level plays an important role in the chronic control of the cell's overall capacity for glucose transport, and this effect is clearly distinct from the acute ability of insulin to activate existing glucose transport carriers. If one considers the $V_{\max }$ of glucose transport as some function of the number of activated carriers, then we would infer that one aspect of insulin's overall in vivo action is to induce an increase in the number of available plasma membrane glucose transport carriers. These carriers would then be available for acute activation by shortterm changes in the plasma insulin concentration.

The results obtained in this study are strongly supportive of this hypothesis. We have measured adipocyte glucose transport in rats after modulating their chronic circulating plasma insulin levels by various combinations of insulin, glucose, and STZ injections. In each instance the maximal capacity for glucose transport varied in the same direction as the plasma insulin level. Thus, when rats were made chronically hyperinsulinemic by a 14-day, gradually increasing, insulin treatment protocol, the $V_{\max }$ of adipocyte glucose transport increased. When rats were made progressively hypoinsulinemic with two different doses of STZ (40 or $55 \mathrm{mg} / \mathrm{kg}$ ) the $V_{\max }$ of transport decreased, and this decrease was greater in the most hypoinsulinemic group.

Inasmuch as Musliner et al. (25) have shown that, in vitro, high media glucose levels can lead to a decrease in the ability of cultured fibroblasts to transport glucose, it seemed important to evaluate the possibility that in the STZ-treated rats it might be the hyperglycemia rather than the hypoinsulinemia which led to the decrease in transport capacity. However, when animals were made hyperglycemic, but not hypoinsulinemic, with glucose injections three times a day, the glucose transport capacity did not decrease. Thus, the decrease in transport $V_{\max }$ after STZ treatment is most closely associated with the hypoinsulinemia rather than hyperglycemia. Although it seems quite unlikely, one cannot rule out the possibility that hypoinsulinemia plus hyperglycemia are necessary to produce a decrease in transport $V_{\max }$. However, this idea seems especially remote because fasting causes hypoinsulinemia, without hyperglycemia, and also leads to a decrease in adipocyte glucose transport $V_{\max }$ (6). Furthermore, Smith (11) has shown that when adipocytes are cultured in the presence of a high glucose level $(5.6 \mathrm{mM})$ their subsequent ability to metabolize glucose is greater than when they are cultured with a low glucose concentration $(1 \mathrm{mM})$. One might also argue that the decreased transport $V_{\text {max }}$ of the high dose STZ-treated animals is a result of the weight loss and catabolic state of these animals rather than the hypoinsulinemia. However, this also seems unlikely because the low dose STZ-treated animals gained weight at a near normal rate (Table I) but still demonstrated a striking decrease in adipocyte transport capacity. Based on the above arguments, plus the findings that changes in $V_{\text {max }}$ values paralleled changes in plasma insulin levels in several entirely different animal models, we believe the data are most consistent with the concept that plasma insulin is a long-term regulator of glucose transport capacity. This conclusion is further strengthened when the individual data were examined. Thus, when 
the results from all the groups were combined, a highly significant positive correlation was found between each animal's plasma insulin level and $V_{\text {max }}$ value in both the basal and insulin-stimulated state.

These conclusions are not dependent on the method of data expression. For example, one could argue that because glucose transport is a membrane phenomenon, transport data should be normalized to plasma membrane surface area rather than to cell number. Although the data presented cannot resolve which method of normalization is most valid, as seen in Table II, despite the fact that adipocyte size varied among the different experimental groups, expressing the data on the basis of unit plasma membrane surface area did not change any of the relationships between plasma insulin levels and $V_{\max }$ values.

Data from other animal studies are also supportive of this relationship. For example, in an extensive series of papers published a number of years ago, Kipnis et al. $(7,8)$ and Morgan et al. $(9,10)$, clearly demonstrated that alloxan-induced diabetes led to decreased glucose transport activity of rat muscle. Although plasma insulin levels were not measured in these earlier studies (7-10), and although the decrease in transport was not directly related to hypoinsulinemia or to the severity of the diabetes, these reports are clearly consistent with the current results. Additionally, Goodman et al. (26) have found decreased glucose uptake by perfused hindlimbs of insulindeficient streptozotocin-treated diabetic rats. Furthermore, as rats are fasted for $24-72 \mathrm{~h}$, plasma insulin levels progressively decline, and this is associated with a stepwise fall in the $V_{\max }$ of adipocyte glucose transport (6). Clearly, all of these studies are consistent with the above described relationship between plasma insulin levels and adipocyte glucose transport.

Lastly, in addition to indicating a new mechanism whereby insulin can serve as a more chronic regulator of glucose homeostasis, the present results may also relate to the insulin resistance of certain diabetic states. For example, severely insulin-deficient, ketosis prone, animals and man have been shown to be insulin resistant (27-29). If hypoinsulinemia can lead to a decrease in maximal transport capacity of target tissues, then the insulin insensitivity of these diabetic states can be readily explained. Similarly, nonketotic adult diabetic patients with fasting hyperglycemia are insulin resistant but secrete decreased amounts of insulin in response to a glucose load (30), and we have recently demonstrated that although these patients have fewer cellular insulin receptors, decreased insulin binding does not account for their insensitivity to insulin's effects (31). It seems possible to speculate, therefore, that the insulin resistance of nonketotic diabetic patients with fasting hyperglycemia is primarily accounted for by a decrease in the glucose transport capacity of insulin's target tissues.

\section{ACKNOWLEDGMENTS}

This work was supported by funds from the Medical Research Service of the Veterans Administration, by a grant from the American Diabetes Association, and by National Institutes of Health grants AM-19905 and AM-20993.

\section{REFERENCES}

1. Morgan, H. E., and J. R. Neeley. 1972. Insulin and membrane transport. Handb. Physiol. 1(Sect. 7): 323-331.

2. Narahara, H. T., and P. Ozand. 1963. Studies of tissue permeability. IX The effect of insulin on the penetration of 3-O-methyl glucose- $\mathrm{H}^{3}$ in frog muscle. J. Biol. Chem. 238: 40-49.

3. Vinten, J., J. Gliemann, and K. Osterlind. 1976. Exchange of 3-()-methyl glucose in isolated fat cells. Concentration dependence and effect of insulin. J. Biol. Chem. 251: 794-800.

4. Olefsky, J. M. 1975. Effect of dexamethasone on insulin binding, glucose transport and glucose oxidation of isolated rat adipocytes. J. Clin. Invest. 56: 1499-1508.

5. Olefsky, J. M. 1978. Mechanisms of insulin activation of glucose transport in adipocytes. Biochem.J. 172: 137-145.

6. Olefsky, J. M. 1976. Effects of fasting on insulin binding, glucose transport and glucose oxidation in isolated rat adipocytes. J. Clin Invest. 58: 1450-1460.

7. Kipnis, D. M., and C. F. Cori. 1959. Studies of tissue permeability. $V$. The penetration and phosphorylation of 2-deoxyglucose in the rat diaphragm. J. Biol. Chem. 234: $171-177$.

8. Kipnis, D. M. 1959. Regulation of glucose uptake by muscle: functional significance of permeability and phosphorylating activity. Ann. N. Y. Acad. Sci. 82: $354-365$.

9. Morgan, H. E., E. Cadenas, D. M. Regen, and C. R. Park. 1961. Regulation of glucose uptake in muscle. II. Ratelimiting steps and effects of insulin and anoxia in heart muscle from diabetic rats. J. Biol. Chem. 236: 262-268.

10. Morgan, H. E., M. J. Henderson, D. M. Regen, and C. R. Park. 1959. Regulation of glucose uptake in heart muscle from normal and alloxan diabetic rats: the effects of insulin, growth hormone, cortisone, and anoxia. Ann. N. Y. Acad. Sci. 82: 387-402.

11. Smith, U. 1974. Studies of human adipose tissue in culture. III. Influence of insulin and medium glucose concentration on cellular metabolism. J. Clin. Invest. 53: 91-98.

12. Rodbell, M. 1964. Metabolism of isolated fat cells. I. Effects of hormones on glucose metabolism and lipolysis. J. Biol. Chem. 239: 375-380.

13. Olefsky, J. M., and G. M. Reaven. 1975. Effects of age and obesity on insulin binding to isolated adipocytes. Endocrinology. 96: 1486-1498.

14. Hirsch, J., and E. Gallian. 1968. Methods for the determination of adipose cell size in man and animals. J. Lipid Res. 9: 115-119.

15. Di Girolamo, M., S. Medlinger, and J. W. Fertig. 1971. A simple method to determine fat cell size and number in four mammalian species. Am. J. Physiol. 221: 850-858.

16. Olefsky, J. M. 1976. The effects of spontaneous obesity on insulin binding, glucose transport and glucose oxidation of isolated rat adipocytes. J. Clin. Invest. 57: $842-851$.

17. Wick, A. N., D. R. Drury, H. I. Hakada, and J. B. Wolfe. 1957. Localization of the primary metabolic block produced by 2-deoxy glucose. J. Biol. Chem. 224: 963-969. 
18. Gliemann, J., K. Osterlind, J. Vinten, and S. Gammeltoft. 1972. A procedure for measurement of distribution spaces in isolated fat cells. Biochim. Biophys. Acta. 286: 1-9.

19. Tsuboi, K. K., and J. C. Petricciani. 1975. Concentrative accumulation (active transport) of 2-deoxy-D-glucose in primate fibroblasts. Biochem. Biophys. Res. Commun. 62: $587-593$.

20. Desbucuois, B., and G. D. Aurbach. 1971. Use of polyethylene glycol to separate-free and antibody-bound peptide hormones in radioimmunoassay. J. Clin. Endocrinol. Metab. 33: 732-738.

21. Renner, E. C., P. G. W. Plagemann, and R. W. Bernlohr. 1972. Permeation of glucose by simple and facilitated diffusion by Novikoff rat hepatoma cells in suspension culture and its relationship to glucose metabolism. $J$. Biol. Chem. 247: 5765-5776.

22. Kletzien, R. F., and J. F. Perdue. 1974. Sugar transport in chick embryo fibroblasts. I. A functional change in the plasma membrane associated with the rate of cell growth. J. Biol. Chem. 249: 3366-3374.

23. Czech, M. P., J. C. Lawrence, Jr., and W. S. Lynn. 1974. Hexose transport in isolated brown fat cells. A model system for investigating insulin action on membrane transport. J. Biol. Chem. 249: 5421-5427.

24. Weber, M. B. 1973. Hexose transport in normal and in
Rous sarcoma virus-transformed cells. J. Biol. Chem. 248: 2978-2983.

25. Musliner, T. A., G. P. Chrousos and H. Amos. 1977. Transport enhancement and reversal: glucose and 3-O-methyl glucose. J. Cell Physiol. 91: 155-168.

26. Goodman, M. N., M. Berger, and N. B. Ruderman. 1974. Glucose metabolism in rat skeletal muscle at rest. Diabetes. 23: 881-888.

27. Reaven, G. M., W. S. Sageman, and R. S. Swenson. 1978. Development of insulin resistance in normal dogs following alloxan-induced insulin deficiency. Diabetologia. 13: 459-462.

28. Martin, F. I. R., and A. E. Stocks. 1967. Insulin sensitivity and ${ }^{131}$ I-insulin metabolism in juvenile-type diabetes. Australas. Ann. Med. 16: 289-296.

29. Martin, F. I. R., and A. E. Stocks. 1968. Insulin sensitivity and vascular disease in insulin-dependent diabetes. Br. Med.J. 2: 81-82.

30. Reaven, G. M., R. Bernstein, B. Davis, and J. M. Olefsky. 1976. Nonketotic diabetes mellitus: insulin deficiency or insulin resistance? Am. J. Med. 60: 80-88.

31. Olefsky, J. M., and G. M. Reaven. 1977. Insulin binding in diabetes. Relationship with plasma insulin levels and insulin sensitivity. Diabetes. 26: 680-688. 